\title{
Sprinkle your investment portfolio with water!
}

\section{Yizheng Jin, Eduardo Roca*, Bin Li and Victor Wong}

Griffith Business School, Griffith University,

Nathan Campus, Queensland 4111, Australia

E-mail: y.jin@griffith.edu.au

E-mail: e.roca@griffith.edu.au

E-mail: b.li@griffith.edu.au

E-mail: v.wong@griffith.edu.au

*Corresponding author

\section{Adrian Cheung}

Department of Finance and Banking,

The School of Economics and Finance,

Curtin University, Perth,

Western Australia 6102, Australia

E-mail: adrian.cheung@curtin.edu.au

\begin{abstract}
We investigate the profitability of water-related investments and their diversification benefits in a portfolio context. Motivated by the need to understand as to whether or not water indices and water funds are desirable vehicles for investment, we analyse the performance of a major water index independently as well as within portfolios. Our results indicate that the water asset class outperforms traditional asset classes, and has the capacity to produce diversification effects in portfolios primarily comprised of listed equity and bond assets. In addition, our study suggests that the diversification benefits of the water asset class are likely to be a result of its superior performance over the stock benchmark, rather than its low correlation with traditional asset classes. Our study provides a valuable contribution to the small, yet growing body of literature on water investments.
\end{abstract}

Keywords: water index; water investment; portfolio theory; profitability.

Reference to this paper should be made as follows: Jin, Y., Roca, E., Li, B., Wong, V. and Cheung, A. (xxxx) 'Sprinkle your investment portfolio with water!', Int. J. Water, Vol. X, No. Y, pp.000-000.

Biographical notes: Yizheng Jin is a $\mathrm{PhD}$ candidate at the Department of Accounting, Finance and Economics, Griffith Business School (GBS), Griffith University, Australia.

Eduardo Roca is currently a Professor of Finance and the Head of the Finance and Financial Planning Discipline at GBS

Bin Li is a Lecturer in Finance at GBS.

Victor Wong is a Lecturer in Finance at GBS 
Adrian Cheung is currently a Senior Lecturer at the Department of Finance and Banking, The School of Economics and Finance, Curtin University, Australia.

\section{Introduction}

The water industry is one of the largest industries in the world. Water experts estimate the size of the global water industry today to be between USD425 billion and USD700 billion per year, while the numbers are poised for considerable growth (Geman and Kanynda, 2007). Unsurprisingly, the water industry has quickly become a hot topic in the past two decades when many countries begin to privatise their water sector.

The increasing importance of the water industry encourages investors' participation in the water sector. In this context, water indices have been introduced to meet the needs of investors who are interested in this market. These indices are designed to assist investors in capturing movements of the water market. Water funds have been also created for investors looking for opportunities in this market. Presently, there are at least nine funds in the form of exchange traded funds (ETFs), open-ended conventional funds and investment trusts, investing in the water industry partially or wholly (Ben-Ami, 2010). These water indices and water funds that reflect risks and returns of the entire water industry market are likely to provide diversification of financial capitals for investors.

Interestingly, research on the profitability of water investments is generally lacking, and investors are ill-informed about the performance of the water industry. Although in the past five years the possibility of including water funds in investment portfolios as alternative assets has generated some interest amongst institutional investors, it has not caught the eyes of academic researchers. Therefore, it will be of interest to understand, through methodologically stringent studies, the potential of using water indices as an alternative investment in addition to traditional investments. In other words, it would be very important to investigate the likelihood of gaining additional profits by adding water indices into investors' existing portfolios.

Our study extends the literature by examining the questions described above. The World Water Index (WOWAX), which is designed to reflect major movements of the water market, will be used to represent the water industry or water market for the purpose of this study. Specifically, the study will involve the following:

1 an analysis of the risk-adjusted returns of the water market

2 an analysis of the relationship between the water market with the stock and bond markets

3 a comparison of the performance between a traditional portfolio consisting of stocks and bonds and portfolios that also include a water index as an alternative asset in addition to stocks and bonds.

The remainder of this article is organised as follows. Section 2 reviews the important work completed in the field of water investment; Section 3 elucidates the development of the hypotheses, followed by Section 4 which discusses the research design; results will be analysed and reasoned in Section 5. A summary and conclusion are presented in 
Section 6, including the implications and limitations of the research and directions for future research.

\section{Literature review}

The comparatively poor performance of traditional investment asset classes (such as stocks and bonds) in recent years urged investors to search for greater returns through investing in alternative asset classes (Campbell, 2008). Early research on alternative investments focused on a small number of asset classes which include private equity, real estate and hedge fund. In the last decade, researchers and investors have expanded their selection to include new classes, such as commodity, infrastructure and water sector. Among the alternative sectors, the water industry has been achieving strong and steady growth. It profits from the growth of world economy as well as from urbanisation and water shortage (Pinsent Masons, 2010). Hence, the increased interest in the water sector in recent years should not come as a surprise.

The traditional way by which investors can participate in the water sector is to directly purchase equities of water companies. However, recently other forms of financial instruments have been introduced allowing more choices for investors to gain exposure to the water market. Water indices and the related ETFs are vehicles developed to mirror the market in meeting investors' needs to take positions in the whole water market rather than in a specific water company. They offer investors the flexibility of buying and selling the whole water market with a single transaction.

The American Stock Exchange (AMEX) introduced the Palisades Water Index (ZWI) in 2003 and started publishing it on a regular basis since 2005 (Geman and Kanyinda, 2007). Following the publication of ZWI, two ETFs - Power Shares Water Resources and Power Shares Global Water - were successively introduced to investors to assist them in keeping track of companies included in the ZWI (Keenan, 2008). There are other ETFs available to investors, such as the Claymore S\&P Global Water which is based on the S\&P Global Water Index, and the First Trust ISE Water which is based on the ISE Water Index (Atkinson, 2009). However, a number of companies included in these water indices generate only a small portion of their revenues from water-related products and/or services. Questions have therefore been raised as to whether these water ETFs can be defined as pure water funds (Kearney, 2008).

Dow Jones and the SAM group (SAM is a Swiss firm that specialises in sustainable asset management) collaboratively introduced WOWAX in 2006. WOWAX is comprised of 20 of the largest publicly traded companies in the water-related business worldwide. Specifically, the component companies are required to have their primary source of revenues in one or more water investment clusters, such as water utilities, water infrastructure and water treatment (Societe Generale, 2006). In the meantime, the French bank Societe Generale, Dow Jones Indexes and SAM launched a certificate SAM sustainable Water Fund replicating the performance of this index, providing investors access to the water industry via WOWAX. The Dutch bank ABN Amro offers a similar product - the $\mathrm{ABN}$ 'Water Certificaat' which is also directly related to WOWAX (Geman and Kanyinda, 2007). As WOWAX only includes companies specialising in water-related business, it is considered an accurate representation of the water market industry. Therefore, in this study, it is chosen to be the tool for examining the water market as a whole. 
To the best of our knowledge, investments in water indices and EFTs and their diversification potential in combination with other asset classes have not yet been studied. The study by Geman and Kanyinda's (2007) is perhaps the best attempt in this field. Their study focuses on the possibility of trading water as a commodity, and taking direct positions in futures contracts and structured notes. Specifically, they evaluate the performance and volatility of WOWAX between December 2003 and June 2006, and find that the index increased by more than $80 \%$ during this period. On top this, they find the volatility of the index to be remarkably low (consistently lower than $12 \%$ for more than half a year from December 2005 to August 2006). In addition, they review WOWAXs performance in relation to the three major commodity investments (i.e., Dow Jones-AIG total return index, Dow Jones-AIG Energy Sub-index and Dow Jones-AIG Petroleum Sub-index). Their results indicate that WOWAX outperformed Dow Jones-AIG total return index, which itself was a particularly successful investment since its start in 2000. Consequently, Geman and Kanyinda (2007) suggest that WOWAX and hence, the water sector to be a good investment choice. However, their study is not without flaws. First, they only examine the performance of WOWAX for the first two and a half years of its life, which is clearly insufficient to draw valuable conclusions. Second, the authors do not investigate the existing water market in-depth, but only briefly review the performance of the two water indices (i.e., ZWI and WOWAX). Third, there has been little discussion of stocks of water-related companies and water index. Fourth, they fail to examine the profitability of these indices from different perspectives. For example, their paper could have additionally explored the relationship between the water asset class and traditional investment asset classes, and the diversification benefits of the water asset class in a portfolio context. Geman and Kanyinda's study contributes to our understanding of the profitability of water investments but their results have marginal value in guiding investors in decision making. Moreover, research on water investments in the post financial crisis period is generally lacking. Our study therefore aims to fill in these important gaps in the literature.

\section{Issues and hypotheses}

The water market is characterised by stable growth rates and high dividend ratios (Doerr, 2008). Investors generally believe that water assets can provide them with desirable risk-return trade-offs, which seems to be the driving force of the current private water investment. However, empirical evidence is lacking in supporting this intuition. Hence, the first hypothesis is formulated as follows:

Hypothesis 1 Investments in WOWAX provide attractive risk-return combinations to investors.

Modern portfolio theory, first developed by Markowitz (1952), states that the risk correlations between various assets and optimal allocation of capital are of foremost importance to investors. Usually, a low or negative correlation is favoured because it provides better diversification effects and reduces the overall portfolio risk to a minimal level.

As the water industry is monopolistic in nature and the earnings of water firms tend to remain comparatively stable (OECD, 2009), the water market is not likely to be easily affected by volatility of economic conditions. It is widely believed that the water asset 
class might have weak relationships with traditional asset classes such as stocks and bonds (Berlant, 2009). Therefore, the second hypothesis aiming to understand this very relationship emerges as:

Hypothesis 2 WOWAX has low correlations with traditional asset classes (i.e., stocks and bonds).

For an alternative investment asset, high risk-adjusted returns or low correlations with other portfolio components alone do not guarantee an enhanced performance of the portfolio. Before choosing an alternative asset, investors need to examine how the additional component(s) might affect the overall portfolio performance. Therefore, to test the risk-return trade-offs of portfolios containing WOWAX, the third hypothesis is formulated as follows:

Hypothesis 3 Adding WOWAX into traditional portfolios will enhance the portfolios' performance.

\section{Research design}

\subsection{Data sample}

In order to assess the profitability of water investment and its diversification potential, it is necessary to first identify the traditional asset classes that are already available to investors. In an ideal investment world, investors are assumed to invest their capital in well-diversified stock and/or bond portfolios. In our study the stock portfolio is represented by the MSCI World Index (MSCIWI), a market capitalisation weighted stock index maintained by MSCI Inc., which is generally accepted as a benchmark for world stock funds. The Barclays Global Aggregate Index (BGAI), a broad-based bond index maintained by Barclays Capital, is chosen to represent the global bond market performance.

WOWAX is employed to reflect economic activity in the water sector. This index is maintained by the Dow Jones Index and the SAM Index; it aggregates the performance of 20 major listed water company stocks, and thus represents a diversified and liquid investment instrument that investors can use to take a long or short position for water sector exposure (Societe Generale, 2006). Moreover, this index is an equally weighted benchmark; that is, the weight of each component company is set at $5 \%$ to maintain an efficient diversification. To keep the index updated, WOWAX is rebalanced every quarter, and its composition is assessed on a semi-annual basis (Societe Generale, 2006).

The data used for this study include daily returns on the three representative indices of the stock, bond and water markets, respectively, for the period between 1st January, 2004 and 31st May, 2012. This time period is selected because WOWAX can only be traced back to as far as the beginning of 2004. All the indices employed in this study are performance indices and on a US dollar basis. The data are obtained from DataStream and the website of Societe Generale. 


\subsection{Key variables and test statistics}

For all the indices, continuously compounded returns are calculated. The return is the natural logarithmic return on the index at time $t$, while $\Delta p_{i, t}$ denotes the rate of change of $p_{i, t}$ (Campbell, 2008):

$$
\Delta p_{i, t}=\ln \left(\frac{p_{i, t}}{p_{i, t-1}}\right) \times 100
$$

Expected return on portfolio $R_{p}$ is:

$$
R_{p}=\sum_{i=1}^{n} w_{i} \mu_{i}
$$

where

$w_{i} \quad$ weights of investment $i$

$\mu_{i} \quad$ mean return on investment $i$

$n$ number of assets.

Standard deviation of the portfolio $\sigma_{p}$ is:

$$
\sigma_{p}=\sqrt{\sum_{i=1}^{n} w_{i}^{2} \sigma_{i}^{2}+2 \sum_{i=1}^{n} \sum_{j=i+1}^{n} w_{i} w_{j} \operatorname{cov}_{i, j}}
$$

where

$w_{i}^{2}$ weights of the individual assets in the portfolio

$\sigma_{i}^{2} \quad$ variance of the return on asset $i$

$\operatorname{cov}_{i j} \quad$ covariance between the return on asset $i$ and $j$.

According to Sharpe (1966), a portfolio's risk-return characteristic can be measured by the Sharpe ratio. A higher Sharpe ratio is associated with higher portfolio efficiency. Gibbons et al. (1989) develop a significance test to compare the Sharpe ratios of more than one portfolio. Given the Sharpe ratios of the two portfolios (i.e., the base one and the enhanced one) $S_{B}$ and $S_{E}$, the following null hypothesis is testable:

$$
H_{0}: S_{E}=S_{B}
$$

According to Gibbons et al. (1989), this hypothesis can be assessed by the following test statistic:

$$
W=\left[\frac{\sqrt{1+S_{E}^{2}}}{\sqrt{1+S_{B}^{2}}}\right]^{2}-1
$$


where

$S_{B}$ the Sharpe ratio of the base portfolio

$S_{E}$ the Sharpe ratio of the enhanced portfolio.

The $W$ statistic is a non-negative number because $S_{E} \geq S_{B}$. Under the null hypothesis, $W$ is equal to zero, which implies that the two portfolios have similar mean-variance efficiencies. A large $W$ means that one portfolio outperforms another in a statistically significant manner, which leads to the rejection of the null hypothesis and the conclusion that the mean variance efficiencies of the two portfolios are significantly different.

The $W$ statistic follows a Wishart distribution, and can be transformed into an $F$-distribution:

$$
\frac{T(T-N-1)}{N(T-2)} W \sim F_{N, T-N-1}\left(\text { given that } S_{E}>S_{B} \geq 0 \text { and } T / N \geq 3\right)
$$

where

$T$ number of observations

$N$ number of assets.

The transformation only applies when $S_{E}>S_{B} \geq 0$ holds (i.e., $W$ must be non-negative). It should also be noted that the power of the test is critically affected by the degree of freedom of the $F$-test, as Gibbons et al. (1989) suggest that the ratio $T / N$ must meet a threshold of $T / N \geq 3$ for the test to be sensitive. This technique can be used to test whether the Sharpe ratio of a mean-variance efficient portfolio is significantly greater than that of a naively constructed portfolio (Cheng and Liang, 2000).

\section{Empirical results}

\subsection{Summary statistics of key variables}

We use daily return data from 1st January 2004 to 31st May 2012 (101 months) for the following three indices: MSCIWI, BGAI and WOWAX. By standardising all the time series to 100, Figure 1 shows that generally, the MSCIWI and the WOWAX present with similar trajectories during the sample period, while the BGAI appears flat.

Figure 1 Standardised indices from January 1, 2004 to May 31, 2012

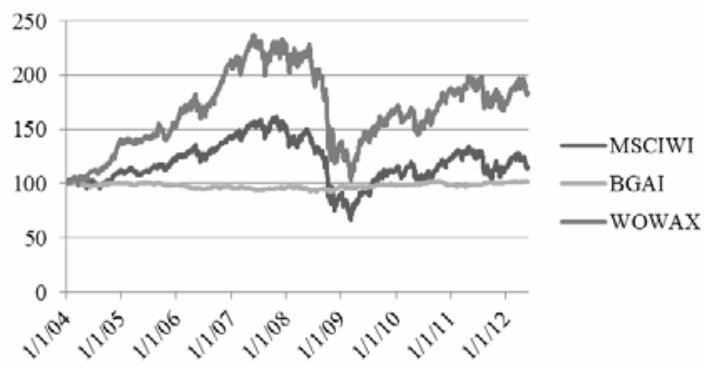


Table 1 illustrates the descriptive statistics for the daily rates of return on WOWAX. The standard deviation of WOWAXs return is $1.17 \%$, indicating a moderate level of risk. Table 1 also reveals a negative skewness of -0.22 and a kurtosis of 8.7 , indicating that a large proportion of the returns resulted from outlying returns. The Kolmogorov-Smirnov test results reject the null hypothesis and suggest that the distributions of the daily returns on the three indices are not normal $(p<0.001)$.

Table 1 Descriptive statistics of returns

\begin{tabular}{lccc}
\hline Statistic & MSCIWI & BGAI & WOWAX \\
\hline $\mathrm{N}$ & 2,195 & 2,195 & 2,189 \\
Mean & $0.006 \%$ & $0.001 \%$ & $0.027 \%$ \\
Minimum & $-7.33 \%$ & $-0.71 \%$ & $-7.44 \%$ \\
Maximum & $9.10 \%$ & $0.73 \%$ & $10.99 \%$ \\
Stand. dev. & $1.15 \%$ & $0.16 \%$ & $1.17 \%$ \\
Skewness & -0.45 & -0.07 & -0.22 \\
Kurtosis & 8.70 & 1.15 & 8.70 \\
Kolmogorov-Smirnov & $4.47^{* *}$ & $1.68 * *$ & $3.71 * *$ \\
\hline
\end{tabular}

Notes: **Denotes statistically significant at the $1 \%$ level.

\subsubsection{Hypothesis 1 - risks and returns}

To test Hypothesis 1, the WOWAX is measured against the MSCIWI and the BGAI in terms of risk and return. As shown in Table 1, the average daily rate of return on WOWAX $(0.027 \%)$ is much higher than that on MSCIWI $(0.006 \%)$. The bond asset offers even a lower mean return as the BGAI exhibits a daily return of $0.001 \%$. It is worth noting that both the lowest and highest daily returns of the MSCIWI and BGAI occur in the second half year of 2008. This is likely to be the result of the abnormal movements (i.e., Global Financial Crisis) in the financial world during that period. However, no such pattern surfaces in the water sector. This could be a good sign when exploring the diversification effects of WOWAX.

Risk of the assets is positively correlated with their returns. The risk-return trade-offs of the three indices are depicted graphically as shown in Figure 2. As expected, BGAI displays both low return and risk. WOWAX which substantially outperforms MSCIWI with only a little added risk is deemed to be more attractive.

Figure 2 Daily risk returns on asset classes

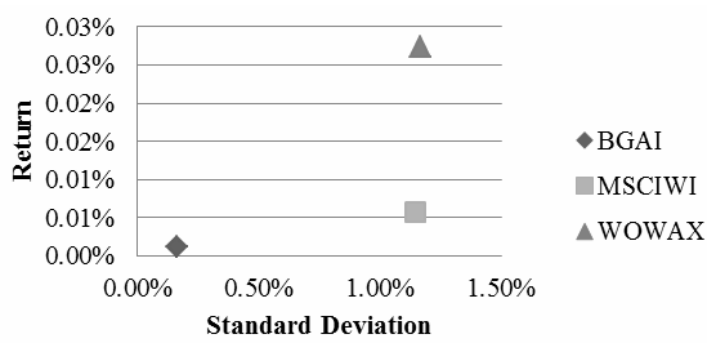


For the following analyses, the overall sample period of 101 months are then divided into three sub-periods as it includes the Global Financial Crisis (GFC) between August 2007 and December 2008 (Hatemi-J and Roca, 2011). Accordingly, the first sub-period ranges from January 2004 to July 2007 including a bull market; the second sub-period from August 2007 to December 2008 including the GFC; and the third sub-period from January 2009 to May 2012 which is post GFC. The daily rates of return on all the three indices vary substantially across the sample period. Their means and standard deviations for the three sub-periods are reported in Table 2.

Table 2 Means and standard deviations for the three sub-periods

\begin{tabular}{lcccc}
\hline \multirow{2}{*}{ Sub-period } & Statistics & \multicolumn{3}{c}{ Index } \\
\cline { 3 - 5 } & & MSCIWI (\%) & BGAI (\%) & WOWAX (\%) \\
\hline Period 1 & Mean & 0.044 & -0.006 & 0.084 \\
& Stand. dev. & 0.587 & 0.141 & 0.734 \\
Period 2 & Mean & -0.143 & 0.008 & -0.128 \\
& Stand. dev. & 1.805 & 0.222 & 1.841 \\
Period 3 & Mean & 0.028 & 0.006 & 0.033 \\
& Stand. dev. & 1.235 & 0.156 & 1.166 \\
\hline
\end{tabular}

Notes: Sub-period 1: January 2004 to July 2007; sub-period 2: August 2007 to December 2008; sub-period 3: January 2009 to May 2012.

The differences between MSCIWI, BGAI and WOWAX are analysed using t-tests. Results in Table 3 indicate that there are no statistically significant differences between the three indices except for sub-period 1 where BGAI significantly underperforms the other two indices.

Table 3 T-test results on the returns on the three market indices from January 2004 to May 2012

\begin{tabular}{lccc}
\hline & MSCIWI-BGAI & MSCIWI-WOWAX & BGAI-WOWAX \\
\hline Full sample period & & & \\
$t$-value & 0.191 & -0.619 & -1.049 \\
df & 4388 & 4382 & 4382 \\
$p$-value & 0.849 & 0.536 & 0.294 \\
\hline Sub-period 1 & & & \\
$t$-value & 2.538 & -1.281 & -3.662 \\
df & 1864 & 1864 & 1864 \\
$p$-value & $0.011^{*}$ & 0.200 & $0.000^{* *}$ \\
\hline Sub-period 2 & & & 1.412 \\
$t$-value & -0.1 .601 & -0.113 & 740 \\
df & 740 & 740 & 0.158 \\
$p$-value & 0.110 & 0.910 & \\
\hline Sub-period 3 & & & -0.705 \\
$t$-value & 0.529 & -0.100 & 1774 \\
df & 1780 & 1774 & 0.481 \\
$p$-value & 0.597 & 0.920 & \\
\hline
\end{tabular}

Notes: *Significant at the $5 \%$ level, and $* *$ significant at the $1 \%$ level. 
Based on the above results, the following conclusions can be made. First, for the full sample period, the rates of return on WOWAX are on average much higher than those on equity indices. This may be partly due to the outperformance of WOWAX within the first sub-period. This finding confirms the previous findings which suggest that the water assets generate higher returns than listed stocks (Geman and Kanyinda, 2007). Second, the equity and water indices generally trounce the bond index. Because of the turbulence that affected the entire financial world, both MSCIWI and WOWAX performed poorly during sub-period 2, with both of their average daily rates of return falling by about $0.2 \%$. In the meantime, the average daily rate of return on the bond index increases considerably. Lastly, in the past four years after the financial crisis, WOWAX presents lower levels of risks but higher average daily rates of return than MSCIWI. It is noteworthy that although there are apparent differences in returns, these differences do not reach statistical significance. This is possibly because our study utilises daily returns where the values are very small and standard deviations are incomparably large.

It can be seen in Table 1 that in the full sample period WOWAX generates a higher average daily rate of return than MSCIWI, but also bears a higher risk. Despite the individual preferences of investors with different degrees of risk aversion, it is undeniable that WOWAX outperforms MSCIWI where its average daily rate return is more than five times higher than that of MSCIWI, but its risk is nearly equal to that of MSCIWI. These results lend support to Hypothesis 1 stating that investments in WOWAX provide attractive risk-return combinations to investors.

\subsubsection{Hypothesis 2 - correlations}

Recall that Hypothesis 2 centres on how returns on the WOWAX vary in relation to traditional assets (i.e., the MSCIWI and the BGAI). If the WOWAX displays low levels of correlation with the MSCIWI, the BGAI, and/or their combinations, we consider it as having good diversification potential.

In order to determine the relationships between the three asset classes, the Pearson's correlation analysis is applied to examine whether their correlation values are significantly different from zero. Table 4 presents the results of correlations between the water, equity and bond indices.

Table 4 indicates that WOWAX significantly correlates with BGAI in a negative manner and with MSCIWI in a positive manner. These relationships appear to have strengthened over time.

The strong association between WOWAX and MSCIWI is initially thought to be partly due to the fact that WOWAX is comprised of stocks of 20 water companies, of which many may have also been included in MSCIWI. However, as MSCIWI consists of more than 1,000 components, its strong correlation with WOWAX cannot be entirely explained by the fact that the latter is also part of the former. In addition, according to Figure 1 and Table 2, the two indices' performances appear to be relatively similar. Hence, the diversification effect of WOWAX to MSCIWI asset is doubtful. 
Table 4 Pearson correlations of daily returns

\begin{tabular}{|c|c|c|c|}
\hline & \multicolumn{3}{|c|}{ Correlation coefficients } \\
\hline & $M S C I W I$ & $B G A I$ & WOWAX \\
\hline \multicolumn{4}{|c|}{ Full sample period } \\
\hline MSCIWI & 1 & $-0.301 * *$ & $0.873 * *$ \\
\hline BGAI & & 1 & $-0.235^{* *}$ \\
\hline WOWAX & & & 1 \\
\hline \multicolumn{4}{|c|}{ Sub-period 1} \\
\hline MSCIWI & 1 & 0.007 & $0.736^{* *}$ \\
\hline BGAI & & 1 & $0.129 * *$ \\
\hline WOWAX & & & 1 \\
\hline \multicolumn{4}{|c|}{ Sub-period 2} \\
\hline MSCIWI & 1 & $-0.353 * *$ & $0.898 * *$ \\
\hline BGAI & & 1 & $-0.331 * *$ \\
\hline WOWAX & & & 1 \\
\hline \multicolumn{4}{|c|}{ Sub-period 3} \\
\hline MSCIWI & 1 & $-0.417 * *$ & $0.899 * *$ \\
\hline BGAI & & 1 & $-0.371 * *$ \\
\hline WOWAX & & & 1 \\
\hline
\end{tabular}

Notes: ${ }^{*}$ Indicates that correlation is significantly different from zero at the 0.01 level.

Despite the co-movement of WOWAX and MSCIWI, the low correlation between WOWAX and BGAI is encouraging, for it provides WOWAX a diversification potential.

Consequently, at this stage of our analysis, the results only partially support Hypothesis 2 which states that WOWAX has low correlations with traditional investment asset classes. In fact, WOWAX is significantly negatively correlated with BGAI, but significantly positively correlated with MSCIWI. This finding casts some doubts on the assumption that investing in stocks of water companies can bring investors diversification benefits.

\subsubsection{Hypothesis 3 - diversification effects}

To seek a better understanding of the risk-return profile of WOWAX in a portfolio context, we calculate the efficient frontiers which integrate the covariance of the assets as well as the overall variations and expected returns.

Two portfolios are created: a base portfolio which is made up of two traditional asset classes (i.e., MSCIWI and BGAI), and an enhanced portfolio which additionally includes WOWAX. For both portfolios, all efficient combinations of assets are modelled to create the efficient frontiers. The results are presented in Figure 3.

Figure 3 shows that the portfolios which optimally combine assets offer improved risk-return trade-offs. It also indicates that the efficient frontier of the enhanced portfolio (stock, bonds plus water) consistently dominates that of the base portfolio (stocks and bonds only), and that there is an apparent disparity between the two efficient frontiers. This suggests that the enhanced portfolio continually generates a higher return than the 
base portfolio at a given level of risk. Given the results, we can conclude that during the time period of investigation, participation in the water industry yields diversification gains even to investors who have already held globally diversified portfolios in the stock and bond markets. Despite WOWAXs strong correlation with MSCIWI, it provides considerable diversification benefits, mostly due to its low correlation with the bond index.

Figure 3 Efficient frontier analyses - full sample period

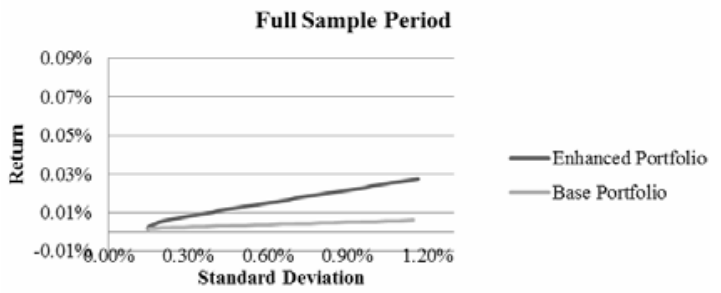

Figure 4 Efficient frontier analyses - three sub-periods

Sub-Period 1

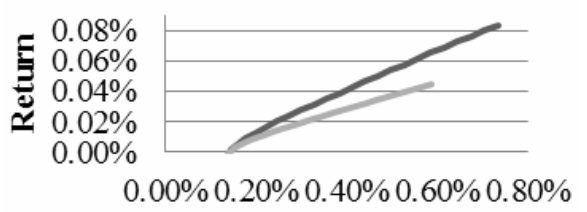

Standard Deviation
Sub-Period 2

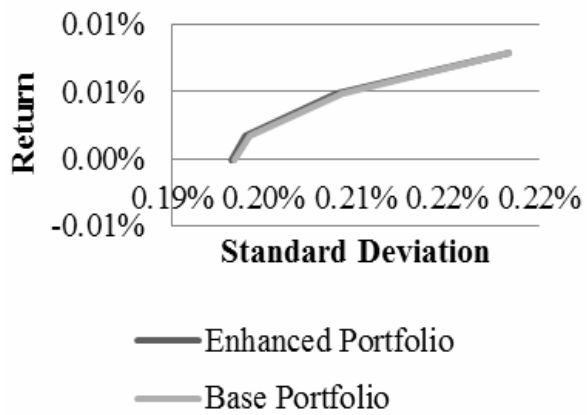

Sub-Period 3

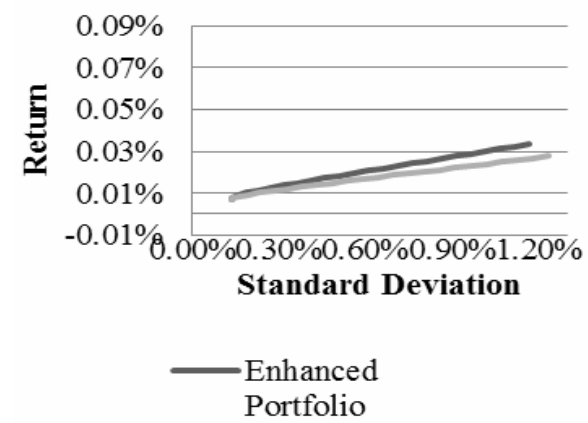

Afterwards, efficient frontiers of the two portfolios in the three sub-periods are created (Figure 4) where similar results are observed in sub-periods 1 and 3. The exception occurs during the financial crisis (sub-period 2). As MSCIWI and WOWAX fail to 
generate positive returns, BGAI accounts for the largest portion of the efficient combinations of both base and enhanced portfolios. Hence, WOWAX shows limited diversification effects for the base portfolio, and the efficient frontiers of both portfolios overlap greatly.

In this study, we assume that mean historical returns are representative of expected returns and that investors can borrow and invest at the risk-free rate (T-bill rate). Hence, the Sharpe ratios of the base and enhanced portfolios, and the F-statistics of these Sharpe ratios are calculated to assess the diversification effects of WOWAX in the following analyses. In order to further evaluate the diversification benefits, optimising and comparing the base and enhanced portfolios are also necessary. The subsequent analyses perform portfolio optimisations. The returns, standard deviations, and optimal portfolio weightings of the indices are reported in Table 5, so that a comparison of the base and enhanced portfolios can be made in terms of the benefits. Moreover, considering that the enhanced portfolios contain WOWAX whose return is not distributed normally (see Table 1), the standard deviation alone is not sufficient to measure the riskiness of the portfolios. Thus, the value at risk $(\mathrm{VaR})$ and conditional value at risk $(\mathrm{CVaR})$ at the $95 \%$ confidence level are also calculated, which help to measure the downside risks (Krokhmal et al., 2002).

Table 5 Diversification properties of WOWAX for different sample periods

\begin{tabular}{lccccc}
\hline & $\begin{array}{c}\text { Base } \\
\text { portfolio }\end{array}$ & $\begin{array}{c}\text { Without limitation in } \\
\text { WOWAX }\end{array}$ & $\begin{array}{c}10 \% \text { in } \\
\text { WOWAX }\end{array}$ & $\begin{array}{c}20 \% \text { in } \\
\text { WOWAX }\end{array}$ & $\begin{array}{c}30 \% \text { in } \\
\text { WOWAX }\end{array}$ \\
\hline Panel A: Full period & & & & & \\
Return & $0.003 \%$ & $0.022 \%$ & $0.005 \%$ & $0.007 \%$ & $0.009 \%$ \\
Stand. dev. & $0.340 \%$ & $0.925 \%$ & $0.344 \%$ & $0.367 \%$ & $0.388 \%$ \\
Sharpe ratio & -0.012 & 0.017 & -0.006 & 0.001 & 0.006 \\
VaR & $0.558 \%$ & $1.479 \%$ & $0.564 \%$ & $0.586 \%$ & $0.620 \%$ \\
CVaR & $0.700 \%$ & $1.857 \%$ & $0.709 \%$ & $0.736 \%$ & $0.779 \%$ \\
F-statistic & & N/A & N/A & N/A & N/A \\
W\% MSCIWI & $31 \%$ & $0 \%$ & $22 \%$ & $14 \%$ & $5 \%$ \\
W\% Barclays & $69 \%$ & $20 \%$ & $68 \%$ & $66 \%$ & $65 \%$ \\
W\% WOWAX & $0 \%$ & $80 \%$ & $10 \%$ & $20 \%$ & $30 \%$ \\
\hline Panel B: Sub-period & 1 & & & & \\
Return & $0.044 \%$ & $0.084 \%$ & $0.048 \%$ & $0.052 \%$ & $0.056 \%$ \\
Stand. dev. & $0.587 \%$ & $0.733 \%$ & $0.584 \%$ & $0.586 \%$ & $0.592 \%$ \\
Sharpe ratio & 0.054 & 0.097 & 0.061 & 0.067 & 0.073 \\
VaR & $0.917 \%$ & $1.116 \%$ & $0.909 \%$ & $0.907 \%$ & $0.913 \%$ \\
CVaR & $1.159 \%$ & $1.419 \%$ & $1.150 \%$ & $1.149 \%$ & $1.157 \%$ \\
F-statistic & & 2.003 & 0.248 & 0.508 & 0.769 \\
W\% MSCIWI & $100 \%$ & $0 \%$ & $90 \%$ & $80 \%$ & $70 \%$ \\
W\% Barclays & $0 \%$ & $0 \%$ & $0 \%$ & $0 \%$ & $0 \%$ \\
W\% WOWAX & $0 \%$ & $100 \%$ & $10 \%$ & $20 \%$ & $30 \%$ \\
\hline
\end{tabular}

Notes: The critical value of $F$ at the $5 \%$ significance level is around 2.6 and all the reported $F$-statistics are smaller than 0.5 . Thus, $p$-values are not calculated. 
Table 5 Diversification properties of WOWAX for different sample periods (continued)

\begin{tabular}{lccccc}
\hline & $\begin{array}{c}\text { Base } \\
\text { portfolio }\end{array}$ & $\begin{array}{c}\text { Without limitation in } \\
\text { WOWAX }\end{array}$ & $\begin{array}{c}\text { 10\% in } \\
\text { WOWAX }\end{array}$ & $\begin{array}{c}20 \% \text { in } \\
\text { WOWAX }\end{array}$ & $\begin{array}{c}30 \% \text { in } \\
\text { WOWAX }\end{array}$ \\
\hline Panel C: Sub-period 2 & & & & \\
Return & $0.008 \%$ & $0.008 \%$ & $0.008 \%$ & $0.008 \%$ & $0.008 \%$ \\
Stand. dev. & $0.221 \%$ & $0.221 \%$ & $0.221 \%$ & $0.221 \%$ & $0.221 \%$ \\
Sharpe Ratio & 0.0014 & 0.0014 & 0.0014 & 0.0014 & 0.0014 \\
VaR & $0.356 \%$ & $0.356 \%$ & $0.356 \%$ & $0.356 \%$ & $0.356 \%$ \\
CVaR & $0.449 \%$ & $0.449 \%$ & $0.449 \%$ & $0.449 \%$ & $0.449 \%$ \\
F-statistic & & 0.0000 & 0.0000 & 0.0000 & 0.0000 \\
W\% MSCIWI & $0 \%$ & $0 \%$ & $0 \%$ & $0 \%$ & $0 \%$ \\
W\% Barclays & $100 \%$ & $100 \%$ & $100 \%$ & $100 \%$ & $100 \%$ \\
W\% WOWAX & $0 \%$ & $0 \%$ & $0 \%$ & $0 \%$ & $0 \%$ \\
\hline Panel D: Sub-period 3 & & & & \\
Return & $0.020 \%$ & $0.028 \%$ & $0.021 \%$ & $0.022 \%$ & $0.022 \%$ \\
Stand. dev. & $0.768 \%$ & $0.909 \%$ & $0.765 \%$ & $0.777 \%$ & $0.780 \%$ \\
Sharpe ratio & 0.0253 & 0.030 & 0.027 & 0.027 & 0.028 \\
VaR & $1.231 \%$ & $1.447 \%$ & $1.232 \%$ & $1.240 \%$ & $1.253 \%$ \\
CVaR & $1.547 \%$ & $1.819 \%$ & $1.549 \%$ & $1.558 \%$ & $1.574 \%$ \\
F-statistic & & 0.077 & 0.018 & 0.032 & 0.047 \\
W\% MSCIWI & $64 \%$ & $0 \%$ & $55 \%$ & $47 \%$ & $38 \%$ \\
W\% Barclays & $36 \%$ & $21 \%$ & $35 \%$ & $33 \%$ & $32 \%$ \\
W\% WOWAX & $0 \%$ & $79 \%$ & $10 \%$ & $20 \%$ & $30 \%$ \\
\hline W & & & & $0.0 \%$ &
\end{tabular}

Notes: The critical value of $F$ at the $5 \%$ significance level is around 2.6 and all the reported $F$-statistics are smaller than 0.5 . Thus, $p$-values are not calculated.

Results from the optimisation of the base and enhanced portfolios are illustrated in Table 5. Panel A depicts the optimised portfolios of the full period, in which the base portfolio is made up of $31 \%$ of MSCIWI and $69 \%$ of BGAI. As expected, the enhanced portfolio's return greatly improves when it includes WOWAX (the daily return of the optimal risky portfolio increases from $0.003 \%$ to $0.022 \%$ ). Without surprise, the improvement of return comes with an increase in the portfolio's volatility, i.e., the standard deviation rise from $0.340 \%$ to $0.923 \%$. To provide a clear risk profile, Table 5 also compares the tail risks and reports the $\mathrm{VaR}$ and $\mathrm{CVaR}$ which are estimated at the 95\% confidence level. Panel A shows that the tail-risk of the optimal portfolio increases after adding WOWAX into the combination (VaR increases from $0.558 \%$ to $1.479 \%$ and CVaR increases from $0.700 \%$ to $1.857 \%$ ). This is because WOWAX has a larger downside risk (lower $\mathrm{VaR}$ and $\mathrm{CVaR}$ ) than MSCIWI and BGAI. However, these extra risks seem to be compensated by the increase in returns. The Sharpe ratio increases considerably from -0.012 to 0.017 , suggesting the existence of diversification benefits. Unfortunately, due to the negative Sharpe ratio of the base portfolio, Gibbons et al.'s (1989) significance test could not be applied in this situation. The F-statistics which allow one to evaluate whether the enhanced portfolios significantly improves the efficiency of the base portfolio are not available in panel A. 
It is worth noting that after optimisation, WOWAX has a weighting of $80 \%$ in the enhanced portfolio. In reality, the participation in the water sector should be no more than a supplement to a widely diversified portfolio. Hence, this portfolio composition $(80 \%$ WOWAX, 20\% BGAI and $0 \%$ MSCIWI) may not be an appropriate recommendation. In order to gain a more realistic valuation, the enhanced portfolio is optimised again with the weightings of WOWAX limited to $10 \%, 20 \%$ and $30 \%$ individually. When the weighting of WOWAX is limited to $10 \%$, the optimal enhanced portfolio consists of a $22 \%$ stake in MSCIWI and a $68 \%$ stake in BGAI. Compared with the base portfolio, this enhanced portfolio's return increases by $86 \%$ but the risk does not increase correspondingly. The standard deviation, VaR and CVaR remain almost unchanged. This suggests that by adding $10 \%$ of WOWAX into the base portfolio, investors could enjoy the diversification benefit without bearing extra risks. As the weighting of WOWAX in the portfolio increases to $20 \%$ and then to $30 \%$, the returns and risk of the portfolios increase accordingly. The same pattern is observed in the Sharpe ratios. These findings are consistent with the results in the previous analyses, indicating that a more advantageous risk-return combination can be achieved by supplementing a base portfolio (of stocks and bonds) with WOWAX. It is also noted that the weighting of BGAI remains stable during the optimisation process, while MSCIWI is replaced by WOWAX gradually. This is likely due to the low correlation between BGAI and WOWAX, and high correlation between MSCIWI and WOWAX.

Panels B, C and D are arranged identically with panel A, displaying the same analyses repeated for three sub-periods. According to panel B, the optimal portfolios in sub-period 1 are comprised without BGAI. It is noted that the optimal base portfolio is formed purely by MSCIWI, and the optimal enhanced portfolio is comprised exclusively of WOWAX. BGAI has a zero stake in all five optimised combinations. These observations are believed to be products of the negative return of the BGAI, and the strong association between WOWAX and MSCIWI.

Panel $\mathrm{C}$ portrays the performance of portfolios in sub-period 2 (the financial crisis period). Both MSCIWI and WOWAX have negative mean returns during the 17 months, while BGAI is the only profitable asset. As a result, all optimised combinations in sub-period 2 are entirely consisted of BGAI. Although WOWAX outperforms MSCIWI in the financial crisis, it still could be abandoned.

Portfolio optimisation for sub-period 3 is shown in panel D. Compared with MSCIWI, WOWAX generates higher returns but has lower risk in the post crisis period. It can be seen that the weight of BGAI is kept stable while MSCIWI is replaced by WOWAX incrementally during the process. This trend leads to growth in the returns, Sharpe ratios and F-statistics.

Overall, the four panels in Table 5 consistently show that with the increase of the weight of WOWAX, the portfolios' returns and Sharpe ratios increase correspondingly. This indicates that the risk-return trade-offs of the portfolios improves as it includes more shares of water investments. The enhanced performance of portfolios is likely to result from the superior risk-return combinations provided by WOWAX as well as its low correlation with BGAI. However, the diversification effect of WOWAX is weakened by its strong positive correlation with MSCIWI.

F-statistics are used to examine the statistical difference between the Sharpe ratios of the base and enhanced portfolios in the three sub-periods (F-statistics not available for the full sample period). Unfortunately, all available F-statistics are too small to be significant (compared with the critical F-value of 2.6 at a $5 \%$ significance level), suggesting that 
there is no statistically significant difference. This finding was in line with the result found by the first significance test (which was illustrated in Table 3). Nonetheless, in Panels A and B, Sharpe ratios of traditional portfolios increase considerably by including WOWAX as an additional component. This is believed to be of economic significance. This discrepancy may cause investors to hesitate in making investment decisions. According to Michael et al. (2009), economic significance should be granted priority over statistical significance. Hence, it is recommended that in the consideration of forming a well-diversified investment portfolio, investors give priority to the economic significance of adding WOWAX into their portfolios.

Based on the present findings, we can conclude that in relation to Hypothesis 3, adding WOWAX into traditional portfolios will enhance the portfolios' performance. However, the evidence fails to reach statistical significance, and the diversification effects are stronger before the 2008 GFC.

To summarise, it is safe to say that WOWAX can be used as a substitute of MSCIWI in a portfolio, but not a replacement for BGAI. Table 5 indicates that when MSCIWI is incrementally replaced by WOWAX, the returns on the portfolios increase and to a certain level, the risk decreases. However, there are no such effects when BGAI are replaced by WOWAX.

\section{Conclusions}

We compare the performance of a water index and the listed equity and bond indices, with the purpose of investigating the profitability of water-related investments and their diversification benefits in a portfolio context. The motivation for our study is derived from the need to understand whether or not water indices and water funds are desirable tools for investment; that is, whether investors can profit from investing in the water industry.

Overall, our findings suggest that the water asset class, or more specifically, WOWAX outperforms the traditional asset classes between 2004 and 2012, and has the capacity to yield diversification effects in portfolios primarily comprised of listed equity and bond assets. These results confirm Geman and Kanyinda's (2007) findings in 2007 where they report that WOWAX generates higher returns but lower risks than listed stocks. Our results are also consistent with the belief that the water sector can be considered as an alternative investment asset class because of its stable growth rates, high dividend ratios and low correlations with traditional asset classes (Berlant, 2009; Doerr, 2008). However, these analyses are not exactly conclusive: our study also shows that the relationship between the water asset class and listed equity class might not be as low as it was thought previously, and the diversification benefits of WOWAX may not be significant during and after the global financial crisis period since 2007 . Hence, investors should be mindful of these issues when making investment decisions.

In contrast to more established alternative asset classes such as private equity and real estate, research on water investments is scarce. Our study contributes to the literature by closing this research gap and expanding our knowledge on the returns and the diversification properties of water investments. However, it is limited by the sample. WOWAX is selected to represent the water asset class. Apparently, a single index cannot track the performance of the whole water market, and focusing exclusively on the performance of WOWAX during the seven years might have weakened the utility of this 
study. Therefore, investigation on other water-related assets (water stocks, indices and ETFs) of which data can be traced back further may provide us with a more comprehensive understanding of the water market.

\section{Acknowledgements}

The authors wish to acknowledge Griffith Business School's valuable trading room facilities which greatly assisted in sourcing data for this research.

\section{References}

Atkinson, W. (2009) 'Water investing', Equities, Vol. 58, No. 1, pp.32-33.

Ben-Ami, D. (2010) 'Saturated', Fund Strategy, April, pp.26-30.

Berlant, N.D. (2009) 'Outlook for the water industry', Wall Street Transcript, Vol. 183, No. 14, pp.1-11.

Campbell, R. (2008) 'Art as a financial investment', Journal of Alternative Investments, Vol. 10, No. 4, pp.64-81.

Cheng, P. and Liang, Y. (2000) 'Optimal diversification: is it really worthwhile?', Journal of Real Estate Portfolio Management, Vol. 6, No. 1, pp.7-16.

Doerr, H. (2008) 'Investing in water utilities', Wall Street Transcript, Vol. 182, No. 1, pp.1-8.

Geman, H. and Kanyinda, A. (2007) 'Water as the next commodity', Journal of Alternative Investments, Vol. 10, No. 2, pp.23-30.

Gibbons, M.R., Ross, S.A. and Shanken, J. (1989) 'A test of the efficiency of a given portfolio', Econometrica, Vol. 57, No. 5, pp.1121-1152.

Hatemi-J, A. and Roca, E. (2011) 'How globally contagious was the recent US real estate market crisis? Evidence base on a new contagion test', Economic Modelling, Vol. 28, No. 6, pp.2560-2565.

Kearney, H. (2008) 'Water, water, everywhere - but investors aren't in synch', On Wall Street, Vol. 18, No. 7, pp.20-20.

Keenan, C. (2008) 'A precious resource: investing in the fate of fresh water', Black Enterprise, February, Vol. 38, No. 7, p.44.

Krokhmal, P., Palmquist, J. and Uryasev, S. (2002) 'Portfolio optimization with conditional value-at-risk objective and constraints', Journal of Risk, Vol. 4, No. 2, pp.11-27.

Markowitz, H. (1952) 'Portfolio selection', Journal of Finance, Vol. 7, No. 1, pp.181-198.

Michael, B.G., Stefan, P., Lars, T. and Mihail, T. (2009) 'Diversification properties of investments in shipping', Journal of Alternative Investments, Vol. 12, No. 1, pp.55-74.

Organisation for Economic Co-operation and Development (OECD) (2009) Private Sector Participation in Water Infrastructure: OECD Checklist for Public Action, Organisation for Economic Co-operation and Development, France, Paris.

Pinsent Masons (2010) Pinsent Masons Water Yearbook 2010-2011, Pinsent Masons LLP, London, UK.

Sharpe, W.F. (1966) 'Mutual fund performance', Journal of Business, Vol. 39, No. 1, pp.119-138.

Societe Generale (2006) Investing in Water - With the World Water Index, Societe Generale [online] http://www.equityderivatives.com/admins/files/ other/comdeai/en/files/38.pdf (accessed 28 June 2012). 